\title{
Reforma \\ Agrária \\ e territorialização da agricultura familiar: 0 caso do Assentamento São Domingos dos Olhos D'Água/Morrinhos (GO)
}

MOACIR JOSÉ DOS SANTOS

Universidade de Taubaté

ALZAIR EDUARDO PONTES

Faculdade de Filosofia e Ciências Humanas de Goiatuba

\section{Resumo}

O artigo discute como a ação dos movimentos sociais de luta por acesso à terra promove mudanças não restritas à apropriação do território, pois se estendem à constituição de uma identidade territorial na medida em que o acesso ao assentamento rural se estabelece e consolida. $\mathrm{O}$ objetivo é analisar o processo identitário estabelecido entre os assentados do assentamento São Domingos dos Olhos D’Água, localizado ao sul do Município de Morrinhos, no Estado de Goiás. A investigação do objetivo pertinente à pesquisa implicou na adoção de uma perspectiva descritiva, da modalidade estudo de caso quanto à natureza das variáveis relativas ao processo de territorialização da luta por reforma agrária, seguida pela abordagem metodológica qualitativa quanto à coleta e análise dos dados. Observou-se no assentamento rural investigado a produção de processos de identificação socioterritorial entre os assentados. Conclui-se que a constituição de um novo território a partir da realização de ações pertinentes à reforma agrária resulta em uma experiência territorial balizada por relações de produção, poder e conflitos mediados na identidade territorial e nas distinções entre o momento de reivindicação da reforma agrária, a ação coletiva, e a fixação à terra, com a reprodução parcial de uma lógica produtiva individual.

Palavras-chave: Agricultura Familiar. Reforma Agrária. Desenvolvimento Local.

Agrarian reform and territorialization of family agriculture: the case of the Settlement of São Domingos dos Olhos D'Água/Morrinhos (GO)

\section{Abstract}

The article discusses how the action of social movements for access to land struggle promotes unconstrained changes to the ownership of the territory, because they extend the establishment of a territorial identity as that access to rural settlement establishes and consolidates. The main objective is to analyze the identity process established between the 
settlers of the settlement São Domingos dos Olhos D'Água, located in south of the city of Morrinhos, state of Goiás. The research adopted a descriptive perspective and the case study method, to identify the variables of the territorialization process of the of the struggle for agrarian reform, followed by qualitative methodological approach to collecting and analyzing data. There was found in the rural settlement investigate, the production of territorial social identification processes between the settlers. It is concluded that the creation of a new territory from carrying out relevant actions of agrarian reform results in a territorial experience imposed by the relations of production, power and conflicts mediated in territorial identity and in the distinctions between the claim time of agrarian reform, collective action, and attachment to land with partial reproduction of an individual productive logic.

Keywords: Family Agriculture. Agrarian Reform. Local Development.

\section{Reforma agraria y territorialización de la agricultura familiar: el caso del Asentamiento São Domingos dos Olhos D’Água/Morrinhos (GO)}

\section{Resumen}

Este artículo discute cómo la acción de los movimientos sociales de lucha por acceso a la tierra promueve cambios no restringidos a la apropiación del territorio, pues alcanzan la constitución de una identidad territorial a la medida en que el acceso al asentamiento rural se establece y se consolida. El objetivo es analizar el proceso identitario establecido entre los asentados del asentamiento São Domingos dos Olhos D’Água, ubicado al sur del municipio de Morrinhos, en el estado de Goiás. La investigación del objetivo implicó la adopción de una perspectiva descriptiva, la modalidad estudio de caso en cuanto a la naturaleza de las variables relativas al proceso de territorialización de la lucha por reforma agraria, seguida por el abordaje metodológico cualitativo en cuanto a la recolección y el análisis de los datos. Se observó en el asentamiento rural investigado la producción de procesos de identificación socio-territorial entre los asentados. Se concluye que la constitución de un nuevo territorio a partir de la realización de acciones pertinentes a la reforma agraria resulta en una experiencia territorial balizada por relaciones de producción, poder y conflictos mediados en la identidad territorial y en las distinciones entre el momento de reivindicación de la reforma agraria, la acción colectiva y la fijación a la tierra, con la reproducción parcial de una lógica productiva individual.

Palabras-clave: Agricultura Familiar. Reforma Agraria. Desarrollo Local.

\section{Introdução}

Os conflitos e os movimentos sociais no campo apresentam uma variabilidade e uma complexidade expressivas. São conflitos que envolvem a luta quanto à posse e uso da terra, às questões do trabalho, à luta por cidadania, às políticas públicas de crédito rural e de subsídios governamentais. Essas lutas ocorrem em um quadro marcado por relações de poder associadas à violência e a intensidade com que se desenvolvem os conflitos no campo. Para Souza (1995), as relações de poder são geradoras de território, e o poder, de acordo com Raffestin (1993, p.58), "visa o controle e a dominação sobre os homens e sobre as coisas", logo, sobre a população e sobre os recursos naturais. O domínio, o controle e a apropriação são materializados na transformação territorial e nos embates estabelecidos neste processo.

No território, segundo Raffestin (1993), há “Poder”, sendo este “poder" 
aquele exercido por representantes dos aparelhos complexos, atores sintagmáticos, que encerram o território, controlam a população e dominam os recursos naturais, como a terra. Esse apoderamento se manifesta por ocasião das relações entre indivíduos: ele é exercido pelos homens e é produzido nas relações entre os homens. Para Saquet (2007), o território expressa a tentativa de um indivíduo ou de um grupo atingir, influenciar ou controlar pessoas por meio da delimitação de uma área geográfica e do controle com o estabelecimento de fronteiras, constituintes de malhas e redes delimitadoras dos campos de ação de cada sujeito. O território é, portanto, essencialmente um instrumento de exercício de poder e deve ser entendido, segundo Souza (1995), como todo espaço definido e delimitado por/e a partir de relações de poder.

Como a territorialização é o resultado da relação entre o domínio e a apropriação simbólica dos espaços em diferentes escalas por diversas classes sociais, podem formar-se diferentes territorialidades simultaneamente. Nesse sentido, para Haesbaert (2004), o território é o produto de uma relação desigual de forças, envolvendo o domínio ou controle político-econômico do espaço e sua apropriação simbólica, ora conjugados e mutuamente reforçados, ora desconectados e contraditoriamente articulados. A pluralidade de circunstâncias implica a constituição de múltiplos territórios. A elaboração de uma identidade social e territorial materializada no espaço, como nos assentamentos rurais, pode fortalecer a luta pela terra mediante a constituição de uma territorialidade percebida como resultado da luta coletiva em defesa da reforma agrária e da agricultura familiar.

Os marcos de referência e controle espaciais são perpassados por múltiplas escalas de poder e de identidade, uma realidade multiterritorial. Ao se tratar de território, é preciso considerar o papel do Estado, responsável por criar as condições básicas para a instituição do território dos grandes produtores, enquanto os trabalhadores rurais, proprietários ou não da terra, ficam marginalizados, daí a territorialização como estratégia de luta por reforma agrária. A apropriação desigual do território e os conflitos nela existentes expressam a concentração de riqueza e poder na sociedade capitalista.

Neste artigo, discute-se como a ação dos movimentos sociais de luta por acesso à terra promove mudanças não restritas à apropriação da terra, mas estende-se à constituição de uma identidade territorial na medida em que o acesso ao assentamento rural se estabelece e consolida. O objetivo é analisar o processo identitário estabelecido entre os assentados do assentamento São Domingos dos Olhos D’Água, localizado ao sul do Município de Morrinhos, no Estado de Goiás. Além da introdução, o artigo apresenta mais cinco seções. A segunda seção é dedicada a contextualizar a reforma agrária e a agricultura familiar no Brasil em relação à luta pela terra e aos processos de modernização produtiva pertinentes à concentração fundiária e à exclusão social no campo. A terceira seção apresenta o método e os critérios utilizados para a coleta e tratamento dos dados da pesquisa de campo. A quarta seção trata da trajetória social e da construção identitária dos trabalhadores rurais assentados no assentamento São Domingos dos Olhos D’Água. A quinta seção trata da construção social da identidade dos assentados após a instalação nos assentamentos. E a última seção apresenta as conclusões examinadas a partir das referências conceituais utilizadas no decorrer do artigo. 
Reforma Agrária e territorialização da agricultura familiar: o caso do Assentamento São Domingos dos Olhos D'Água/Morrinhos (GO)

\section{Reforma agrária e agricultura familiar no Brasil}

A questão agrária no Brasil está associada a conflitos provocados com o modelo fundiário predominante no País. A luta por reforma agrária no Brasil adquire visibilidade a partir das décadas de 1940 e 1950, com as Ligas Camponesas, organizações de trabalhadores rurais organizadas com o apoio da Igreja Católica. Com o aumento do número de conflitos no campo, no primeiro ano da Ditadura Militar (1964), foi criado o Estatuto da Terra que regulamentava a reforma agrária e a produção agropecuária. Uma das medidas foi a criação do Instituto Nacional de Colonização e Reforma Agrária-INCRA. Segundo Martins (1984), o Estatuto da Terra objetivava desmobilizar a luta pela reforma agrária conduzida pelas Ligas Camponesas.

Entre 1964 e a década de 1980, a reforma agrária foi radicalmente desacelerada mediante a militarização da questão agrária, caracterizada sob a perspectiva da segurança nacional. Com essa premissa, os assentamentos eram instalados somente em regiões mais distantes e com baixa densidade populacional, como as regiões Norte e Centro Oeste. Ao mesmo tempo, essa política almejava reduzir as tensões no campo ao afastar os trabalhadores sem-terra da contestação à concentração da propriedade da terra.

Durante a Ditadura Militar, subordinou-se a agricultura ao capital industrial com o aumento de concentração da propriedade de terra sob as políticas desenvolvimentistas implementadas no período, particularmente com a modernização da agricultura e a consolidação de complexos agroindustriais (IANNI, 1986). No âmbito social, a expropriação dos trabalhadores rurais agravou a questão agrária. A modernização da agricultura provocou mudanças nas relações de produção e criou um exército industrial de reserva latente e intermitente. A mão de obra que residia no campo foi substituída pelo trabalhador temporário, expulso do campo com o processo de modernização e residente nos centros urbanos. Nesse momento, destacam-se os boias-frias, produto do processo de proletarização dos trabalhadores rurais (FERNANDES, 2005). O trabalhador boia-fria, ainda presente em quase todo o País, é fruto tanto de uma política agrária que não assiste o trabalhador rural, quanto da expropriação da terra associada ao êxodo rural para os centros urbanos pertinente à formação do exército industrial de reserva e sua reprodução ampliada. A expropriação da terra desses trabalhadores é uma estratégia de reprodução das relações capitalistas de produção no campo.

Com o restabelecimento da democracia a reforma agrária contou com apoio de instituições da sociedade civil como a Conferência Nacional dos Bispos do BrasilCNBB, Movimento dos Trabalhadores Rurais-MST, partidos políticos, e dos próprios trabalhadores rurais organizados em sindicatos. Segundo Oliveira (2001), na década de 1980, a CNBB destacou a reforma agrária ao elegê-la como tema da Campanha da Fraternidade de 1980. Um documento sobre a terra foi elaborado para subsidiar a discussão nas Comunidades Eclesiais de Base-CEBs. Fomentava-se nas periferias das cidades brasileiras a discussão sobre a situação de pobreza da maioria da população, com a formação de lideranças comunitárias e projetos para reformas sociais. A conquista da terra foi uma delas. Assim, com o aumento da pressão social, 
também cresceu a violência dos latifundiários, naquele momento praticada como recurso extremo para reter a propriedade da terra.

A concepção dos assentamentos rurais parte da ideia de justiça social no campo, de fixar trabalhadores rurais em pequenas propriedades familiares (BERGAMASCO; NODER, 1996). A pequena propriedade e a agricultura familiar como modelo de desenvolvimento encontram barreiras históricas relativas à precariedade das políticas públicas para o setor e o próprio modelo de organização econômica da agricultura. Desde o período colonial até a década de 1930, preponderou o setor primário como base para a obtenção de recursos via exportação de produtos agrícolas. Com a industrialização substitui-se o modelo de desenvolvimento com base na importação de produtos manufaturados por uma industrialização, mais vigorosa, com a transferência de recursos da agricultura para outras áreas da economia. Após o golpe militar de 1964, os governos militares patrocinaram a modernização do latifúndio em detrimento de políticas públicas de fomento aos pequenos produtores, provocando o êxodo rural com a migração dos trabalhadores rurais para os grandes centros urbanos (TEIXEIRA; MARTIN, 1988). A consequência desse modelo concentrador de renda é a extrema desigualdade econômica. Esse processo gerou aglomerações urbanas onde pessoas vivem em condições precárias, comprometendo até mesmo a própria cidadania.

Segundo Oliveira (1997), o desenvolvimento da agricultura em um ambiente capitalista é perpassado pela indagação constante quanto à permanência ou ao fim da pequena propriedade e da agricultura familiar. Para Martins (1980), no modo de produção capitalista, os trabalhadores rurais estão sujeitos a um processo de destruição e recriação pertinente à articulação entre a produção capitalista com meios e formas não capitalistas de produção. Nesse sentido, para Saquet e Santos (2010), há a combinação entre os mecanismos do Estado e os detentores do capital, benéfica à expansão do capital e sua reprodução ampliada, tudo articulado de forma legal, pois tem amparo da Constituição em vigor, o que implica em constante ameaça aos agricultores familiares e conflitos pertinentes à posse da terra.

Segundo Fernandes (2000), espacialização e territorialização são tipos e formas de ocupação, respostas ao conflito quanto à posse da terra. O processo de ocupação é a forma de luta por acesso à terra. Essas ocupações ocorrem, predominantemente, em regiões onde o capital já se territorializou. Os trabalhadores rurais ocupam latifúndios, terras devolutas e/ou griladas. Os assentamentos materializam o processo de territorialização na conquista de uma gleba de terra para o trabalho, em desfavor à terra de especulação, exploração e negócio. Para Fernandes (2000), os movimentos territorializados são formados pela luta de diferentes categorias e sua composição pode ter duas formas: movimento sindical ou movimento social. Esses movimentos são apoiados por diferentes instituições em ações conjuntas ou em ações específicas. As formas de apoio são o fomento financeiro e ações políticas que se materializam por meio de articulações e/ou alianças.

O movimento social pode receber apoio e/ou estar vinculado a alguma pastoral da Igreja Católica, como a Comissão Pastoral da Terra-CPT ou Pastoral Rural. Da mesma forma, pode receber apoio de centrais sindicais, partidos políticos e organizações não governamentais. O movimento sindical, igualmente, pode receber apoio dessas instituições com articulações e/ou alianças (STEDILE, 2002). A 
territorialização acontece com a ocupação da terra. Nessa ótica, nasce o principal movimento social de luta pela terra: o MST. Na visão desse movimento, o território é tido como a identidade daqueles que o ocuparam, levando em consideração a dimensão simbólica, cultural, material, econômica, política, social e histórica dos indivíduos ou grupo social.

Para Magno (2011), a dimensão territorial é um dos fatores fundamentais para as análises sobre o desenvolvimento rural. Essa perspectiva rompe a redução do território apenas à sua base física, pois possibilita captar a rede de relações territoriais e o capital humano dos espaços ocupados. Para Abramovay (2000), mais que uma base física para as relações entre indivíduos e empresas, o território possui um tecido social, uma organização complexa feita por laços transcendentes aos seus atributos naturais e dos custos de transporte e comunicações. O território representa uma gama de relações com raízes históricas, configurações políticas e identidades cujo papel ainda é pouco conhecido no próprio desenvolvimento econômico.

Bourdieu (1992) ressalta que qualquer mudança social, econômica e política de um grupo, ou de sujeitos, pode levar a conflitos na sua posição social, consequentemente na sua identidade. Bourdieu demonstra como o campo de possibilidades da formação da identidade dos sujeitos está vinculado às suas trajetórias sociais, por sua vez, associadas ao habitus e aos costumes vivenciados por agentes aptos a induzir certa disposição em participar de determinados processos sociais. Seguindo essa mesma perspectiva dinâmica dos constructos identitários, o conceito de economia moral de Thompson (1998) é uma ferramenta pertinente para análise das relações dialéticas articuladas a diferentes espaços e tempos na construção da identidade do sem-terra e também no interior de um assentamento rural. Para Thompson, a economia moral pauta-se na concepção de retribuição justa para o trabalho, daí sua pertinência para o entendimento da relação entre os assentados da reforma agrária e o território.

A identidade, no entanto, não é constituída somente com a conquista da terra e a construção de um novo espaço rural. As experiências anteriores à territorialização contribuem para a formação da identidade territorial dos assentados. Assim, na análise do assentamento e dos conflitos ali existentes, empregam-se os conceitos de Bourdieu e Thompson para se compreender quais elementos sociais, culturais, econômicos ou políticos pertinentes à realidade dos assentados estão relacionados à construção de diferentes territorialidades e experiências sociais territorializadas (MAGNO, 2011).

Becker e Bandeira (2003) corroboram essa perspectiva ao afirmar que a identidade regional é um produto da história. A identidade regional resulta de processos políticos, sociais e culturais associados às ações dos agentes sociais em um determinado território, pois há o compartilhar de experiências comuns. A formação de uma identidade regional pode fortalecer os alicerces para o desenvolvimento regional, uma vez que os atores integrantes dessa região estarão em busca de um interesse mútuo. Porém, faz-se necessário ressaltar a formação de identidades territorializadas como um processo heterogêneo, pois é perpassado por relações econômicas e sociais constituintes de diferentes posições de classe. Nesse sentido, a identidade territorial do assentado da reforma agrária é diferente daquelas dos sujeitos sociais com experiências distintas. Referencias territoriais 
comuns não produzem concepções homogêneas entre os habitantes de um território com trajetórias sociais distintas.

Essa percepção é fundamental para se entender como se dá a territorialização dos movimentos sociais relacionados à reforma agrária e sua associação a um modelo econômico pertinente á agricultura familiar. A reforma agrária e a agricultura familiar implicam, para sua viabilidade, na constituição de políticas públicas adequadas as suas condições, especialmente quanto à não reprodução da lógica produtiva do agronegócio. A tentativa de se reproduzir, no âmbito da agricultura familiar, os mecanismos de produção e comercialização do agronegócio pode inviabilizar a subsistência da pequena propriedade e das possibilidades a ela associadas. Sob esta perspectiva Abramovay (2000) e Veiga (2005) atribuem à agricultura familiar a possibilidade de desempenhar um importante papel para um desenvolvimento mais igualitário, em razão do envolvimento comunitário, pois, de alguma forma, seja na produção, na assistência técnica ou na comercialização o processo é socializado com intuito de viabilização da atividade, com a instituição de novas relações sociais. Desse modo, os assentamentos da reforma agrária e a agricultura familiar contrapõe-se à lógica do agronegócio e somente desta forma podem subsistir, o que implica no estabelecimento de uma identidade territorial específica à trajetória social dos assentados.

\section{Método}

A investigação do objetivo pertinente à pesquisa, analisar o processo identitário estabelecido entre os assentados do assentamento São Domingos dos Olhos D'Água, implicou na adoção de uma perspectiva descritiva, da modalidade estudo de caso quanto à natureza das variáveis pertinentes ao processo de territorialização da luta pela reforma agrária, seguida pela abordagem metodológica qualitativa quanto à coleta e análise dos dados. Frente a essa premissa, a modalidade de investigação estudo de caso constitui a técnica que mais se adaptou às necessidades da pesquisa. Entre os aspectos investigados, destacamse: i) a origem dos trabalhadores rurais sem-terra; ii) as instituições que coordenaram e apoiaram o movimento de ocupação e a organização na chegada ao acampamento; iii) a forma de distribuição dos lotes pelo INCRA; iv) a produção dos assentados; v) e as políticas públicas desenvolvidas no assentamento, entre outros.

A análise realizada orientou-se mediante as referências apresentadas por Bardin (1997) e Franco (2003), por adequar-se ao objetivo proposto. Em campo, no assentamento São Domingos dos Olhos D'Água, procurou-se recuperar as lutas e os conflitos da fase de ocupação até a posse definitiva dos lotes, e ainda descrever os desafios e a luta para permanecer no território tanto na fase de acampamento como de assentamento, tomando como parâmetro Bourdieu (1992) e Thompson (1998). O trabalho dos respectivos autores fundamentou os critérios adotados durante a investigação como: i) conhecer as origens sociais do grupo; ii) as experiências de trabalhos anteriores e recentes; iii) as formas de organização social pelas quais os assentados passaram até a conquista de terra; iv) as características culturais do lugar de origem, presentes ou ausentes no local de destino; v) a relação com a terra; vi) o processo migratório; vii) a produção e a produtividade dos lotes; 
Reforma Agrária e territorialização da agricultura familiar: o caso do Assentamento São Domingos dos Olhos D'Água/Morrinhos (GO)

viii) e a variabilidade de culturas para o autoconsumo dos trabalhadores rurais assentados e para abastecimento do mercado local.

As entrevistas realizadas com os moradores do assentamento São Domingos dos Olhos D’Água permitiram caracterizar a luta pelo assentamento, com início no ano de 1996 e que se estendeu até o ano de 2002, quando o INCRA desapropriou a fazenda e deu início, em 2004, à distribuição da terra em forma de lotes a 86 famílias. Diante do exposto, o recorte temporal do estudo foi o período compreendido entre 1996 e 2010.

A unidade de análise desta pesquisa envolve boa parte dos assentados do Plano de Assentamento-PA São Domingos. Trata-se, portanto, de uma pesquisa por acessibilidade, pois a intenção era atingir os 86 indivíduos detentores da posse de cada um dos lotes de terra distribuídos pelo INCRA. Todavia, alguns fatores limitaram essa meta, o que implicou na entrevista de 72 parceleiros. Para melhor compreensão da forma de ocupação e territorialização do espaço rural, o tipo de entrevista utilizado foi a semiestruturada, com o intuito de comparar as percepções dos entrevistados em contraponto às versões oficiais grafadas nos documentos e publicações que registraram os conflitos existentes na trajetória do assentamento.

O levantamento de campo foi realizado mediante a aplicação de um roteiro de entrevista semiestruturada. O instrumento utilizado na pesquisa de campo foi aplicado em todos os assentados, participantes ou não, da Cooperativa e da Associação de Agricultores existentes no assentamento, e deveria totalizar 86 indivíduos, permitindo ao pesquisador fazer uma leitura dos documentos oficiais e também das entrevistas, dos enfrentamentos ocorridos no processo de ocupação e posse da terra do assentamento objeto de estudo.

A entrevista foi formatada com aproximadamente 60 enunciados, divididos em nove eixos, a saber: identificação do entrevistado e tempo de posse do lote; identificação da trajetória social e construção identitária do assentado; processo de formação e constituição do assentamento rural; o motivo da mudança para o assentamento, quem mais ajudou no processo de ocupação, e como o lote foi adquirido; o cotidiano no assentamento; redes sociais estabelecidas na comunidade; identificação da forma de trabalho na localidade; identificação com a terra; e a questão da alteridade: como é a relação de sociabilidade e diferença entre o indivíduo em conjunto e a unidade.

\section{Trajetória social e construção identitária}

Ao analisar os dados coletados nas entrevistas realizadas no assentamento São Domingos dos Olhos D'água, nos meses de dezembro de 2013, janeiro e fevereiro de 2014, ficou evidente que o tempo de residência do parceleiro no assentamento é, em sua maioria, o mesmo de existência do assentamento. Poucas unidades tiveram realocação após 2004, ano em que a terra foi desapropriada e entregue aos acampados remanescentes no local e aos demais trabalhadores rurais sem-terra cadastrados no INCRA para assentamento. Entre os 72 entrevistados, todos titulares dos lotes, constatou-se que apenas 26 eram remanescentes das 85 famílias que ocuparam, pacificamente a fazenda São Domingos dos Olhos D'Água em 1997. Portanto apenas $32 \%$ conseguiram vencer os quase sete anos de acampamento. Outros 12 assentados só chegaram ao local mais recentemente, há 
menos de cinco anos em relação ao período da coleta de dados, e também foram assentados pelo INCRA, ou ainda esperam pela regularização em trâmite no órgão.

Observou-se que $32 \%$ dos parceleiros entrevistados resistem no local desde a formação do acampamento, em 1997. Outros 40\% ingressaram no território somente no ato da regularização: foram capitaneados pelo INCRA e são oriundos de outros acampamentos ou dos cadastrados da entidade de outras regiões. Os substitutos daqueles que por algum motivo desistiram, ou foi permitida a sua substituição pelo INCRA, como é o caso das pessoas que adoeceram e não tinham familiares para manusear o lote e torná-lo produtivo na forma exigida pelo INCRA completam o conjunto de entrevistados quanto às formas de participação na constituição do assentamento. Ressalta-se que as famílias não participantes da fase de acampamento foram selecionadas pelo INCRA e submetidas à apreciação da Associação de Moradores do Assentamento São Domingos dos Olhos D’Àgua para depois de aceitas tomarem posse do lote disponível.

Na sequência, buscou-se identificar a trajetória social e construção identitária do assentado. Percebeu-se que quase todos os assentados são pessoas excluídas de vários segmentos sociais, dentre eles: trabalhadores urbanos, trabalhadores rurais, boias-frias, meeiros e arrendatários. Um dado observado, reflexo do processo de exclusão e exploração comprometedor da solidificação da agricultura de pequeno porte e familiar no País, é em relação ao local e o tipo de trabalho desenvolvido no local de origem, antes da migração para o assentamento São Domingos dos Olhos D’água. A maioria dos responsáveis pelas famílias assentadas vivia ou trabalhava na zona rural nos municípios de origem como agricultores (17\%), como posseiros (1\%) ou meeiros (3\%), ou ainda como assalariados rurais (53\%). Outros $8 \%$ eram compostos por pessoas que trabalhavam como comerciantes e prestadores de serviços em geral, de maneira informal, e apenas $4 \%$ declararam ser trabalhadores urbanos. Esses dados remetem à lógica caracterizada por lanni (1986) subordinação da agricultura ao capital industrial com a concentração da posse da terra resultante das políticas desenvolvimentistas implementadas pelos governos militares -, que possivelmente levou muitos dos assentados a experimentarem o processo de expropriação de terras e dos meios de trabalho nas décadas de 1960, 1970 e 1980, do século passado, quando os projetos desenvolvimentistas do Estado paulatinamente estimularam o êxodo rural em todas as regiões do País. Nesse processo, muitos trabalhadores experimentaram o trabalho urbano e voltaram ao campo com a luta pela terra. As entrevistas demonstram essa realidade quando se arguiu sobre o local de nascimento do respondente: mais de $80 \%$ não é natural de Morrinhos, município onde está situado o assentamento, e sim de outras cidades de Goiás ou até mesmo de outros estados.

Dos 72 assentados, apenas 29 eram associados a sindicatos ou a movimentos sociais antes de residirem no assentamento São Domingos dos Olhos D'água, e a motivação dessa filiação foi a busca de proteção e a conquista de um pedaço de terra. Já em relação ao significado de ter um pedaço de terra, os paceleiros apontaram, em primeiro lugar, a volta às origens; em segundo, o auto sustento; e em terceiro, trabalhar por conta própria, sem patrão. Esses significados somente são percebidos efetivamente com a conquista de um território articulado nos moldes do sistema tridimensional, apresentado por Raffestin (1993), mediante a 
associação entre a sociedade, o espaço e o tempo em busca da maior autonomia possível, compatível com os recursos disponibilizados.

Quando inquiridos sobre a ajuda dos movimentos sociais de luta pela terra para a conquista do assentamento os depoentes atribuíram ao Sindicato dos Trabalhadores Rurais de Morrinhos-STRM, a Federação dos Trabalhadores Rurais na Agricultura Familiar do Estado de Goiás-FETAEG e à CPT atuação imprescindível para a aglutinação das pessoas e sua permanência no acampamento. Essas entidades contribuíram com apoio político e material para amenizar as dores e privações da fase de acampamento. Nessa questão, incluiu-se também o INCRA como órgão que muito ajudou na conquista. A participação efetiva e constante do órgão oficial da reforma agrária se deu em razão da dificuldade para a emissão de título de posse da propriedade para os assentados, objeto de batalha judicial caracterizada por ações cautelares, agravos e mandados de segurança.

Nas entrevistas, os assentados ressaltaram o medo da pistolagem, pois, durante o processo de ocupação, capangas e capatazes incessantemente rondavam os três acampamentos distribuídos pela propriedade. Em pesquisa documental constatou-se o registro de várias denúncias formais e a publicação de inúmeras notícias sobre esses conflitos em jornais e informativos da CPT. Os poderes legalmente constituídos pouco fizeram no processo de ocupação e posse dos lotes para garantir a efetividade da segurança, apenas o poder judiciário não se eximiu de sentenciar os processos relacionados aos assentamentos. A ocupação, apesar do sucesso quanto à desapropriação da propriedade, não passou ilesa quanto à tensão inerente aos conflitos e à violência presentes no processo de reforma agrária.

As dificuldades experimentadas refletem-se na valorização da vivência coletiva e no conhecimento sobre o território do assentamento. Observou-se nos relatos a ciência dos assentados quanto à história do assentamento. O nome, por exemplo, refere-se ao córrego São Domingos dos Olhos D'água, que corta a fazenda, e a própria terra desapropriada também possuía essa denominação. Por esse motivo, os líderes da época preferiram manter a denominação para o assentamento. Também era do conhecimento de todos, principalmente dos mais antigos na luta, que a propriedade era improdutiva e que os impostos não eram recolhidos há anos aos cofres das fazendas públicas.

Os parceleiros relatam o ingresso na luta por reforma agrária como a possibilidade de conquistar a terra e com ela obter a recuperação da dignidade e a provável constituição de um patrimônio familiar e, principalmente, não mais viver da dependência de patrões. O ideal de autonomia e da terra enquanto patrimônio são as principais motivações apresentadas nos relatos sobre a participação na luta pela terra no PA São Domingos dos Olhos D'água, além, é claro, da vontade de retornar a uma condição social, a de produtor, que muitos vivenciaram no passado. No depoimento de um dos assentados, percebe-se a dimensão do processo de territorialização:

[...] Por isso, mesmo com todas as adversidades enfrentamos frio, calor, e até bala para conseguir transformar o acampamento em assentamento, tendo a conquista do pedaço de terra como a principal referência (ENTREVISTA 6, 2014).

A principal motivação para a reivindicação da desapropriação que originou o assentamento foi a possibilidade de voltar à terra, retornando a uma condição social 
experimentada no passado, seja pelo próprio assentado ou por seus ascendentes, e também a oportunidade de conquistar autonomia no trabalho, de deixar a condição de trabalhador assalariado e dependente de patrão e passar a ser dono do próprio tempo de trabalho. Esses dois itens correspondem a $61 \%$ das respostas dos entrevistados. Outros $27 \%$ apontaram a oportunidade de deixar um patrimônio familiar para os filhos. Além desses quesitos, registrou-se também que $12 \%$ viam a luta pela terra e a conquista do lote como uma maneira de subsistência, de viver apenas da terra.

Os dados mensurados remetem ao entendimento que a terra passou a figurar como o principal mote da luta dos membros do PA São Domingos dos Olhos D’água. Os depoimentos transcritos a seguir também corroboram as considerações dessa questão:

\begin{abstract}
[...] Meu sonho era ter minha vida de volta. Queria ter um lugar pra poder criar os filhos com dignidade e tranquilidade. Longe da vida da cidade grande e da violência. Não queria que eles passassem o que eu passei na vida, então eu via na reforma agrária uma possibilidade disso. De mudar de vida, mas essa mudança era uma reviravolta meio que já vivida no passado, no passado que eu trabalhava na terra, viu, viver da terra e longe das peripécias da cidade grande. Hoje meus filhos adoram isso aqui, apesar de faltar alguma coisa essa casa aqui, é nossa, lutei por isso aqui e consegui, isso é meu [...]. (ENTREVISTA 12, 2014).

[...] Era nas reuniões, lá no sindicato de Morrinhos que a gente conversava bastante e apareciam as expectativas de todos. Nessas reuniões quando está todo mundo junto, fomos criando as condições para enfrenta a luta, condições política né. $\mathrm{Na}$ verdade não tivemos muitos problemas, pois era todo mundo com um único objetivo apesar de alguns desconhecerem a luta, mas eles confiavam que podia dar certo. Aí não foi muito complicado, juntamos todos com os mesmos sonhos, sonhos que muitos já carregavam a tempo. Você viu ai por essas andanças sua né, muita gente não é de Morrinhos mas suas origens era da roça, todos tem histórias de vida na zona rural. Mesmo aqueles daqui de Morrinhos eles também sempre foram ligados à zona rural. Então não foi difícil falar da importância da terra, e da possibilidade de conquistá-la. O mais complicado foi fazer com que eles mudasse de opinião sobre os sem terras, pois a imagem que a mídia passa é muito ruim. Isso foi difícil, eu acho isso um crime. Mas no fim o sonho foi maior e deu certo [...]. (ENTREVISTA 12, 2014).
\end{abstract}

Segundo Wanderley (1995), a conquista de um pedaço de terra é um símbolo que une as pessoas em um processo de luta, inserindo-as na condição moral de manutenção e organização de uma categoria: os sem-terra, pois a conquista da terra é sinônimo de sobrevivência da família assentada. A história da luta pela terra pode ser definida, para Wanderley, como o registro das lutas dentro da sociedade por espaços de autonomia econômica.

$\mathrm{Na}$ análise das entrevistas, verifica-se que apenas cinco famílias entrevistadas têm alguma experiência anterior com acampamentos de trabalhadores sem-terra. $A$ maioria dos entrevistados, 67, participou apenas dessa ação de reforma agrária. Constata-se a relevância das mobilizações locais como fator instigante à construção da identidade social de sem-terra, pois os assentados não são oriundos de experiências anteriores com movimentos sociais, e sim engajados na luta por articulações de lideranças do STRM, responsável por realizar reuniões e politizar os trabalhadores rurais. 
Reforma Agrária e territorialização da agricultura familiar: o caso do Assentamento São Domingos dos Olhos D'Água/Morrinhos (GO)

Mais da metade dos parceleiros são remanescentes do acampamento, embora apenas 26 parceleiros sejam remanescentes do momento da ocupação. Segundo relatos, como a demora foi longa, sete anos, muitos desistiram e outros ocuparam as vagas. Percebe-se, nos depoimentos da maioria, que o sentimento de pertencimento ao grupo foi aguçado na fase de acampamento. Frases como "no acampamento era uma família só" e "o povo tinha mais união na época do acampamento" mostram coesão na fase de acampamento, diferentemente da fase de assentamento, quando esse sentimento de pertencer ao grupo parece ter-se reduzido, com a ocorrência da expressão "agora é cada um por si".

Assim, a experiência do acampamento se apresentava como um ritual de passagem, no sentido dado por Turner (1974), e nesse estágio a identidade social se revelava com a união em prol do objetivo comum. O acampamento foi o símbolo da luta pela terra com uma série de nuances inerentes a ele. Para Turner, são três as situações que caracterizam o ritual de passagem: a) homogeneidade; b) igualdade, e c) ausência de propriedade material. Esses fatores impedem a distinção de indivíduos em um grupo. Todas as situações expostas por Turner podem ser detectadas nos relatos sobre a fase de acampamento: todos estavam sob a lona preta; havia cooperação e mutuamente se revezavam para manter a segurança e a organização no local; havia articulações para manter a união como forma de pertencimento a um grupo objetivo comum; e havia, também, o fator exclusão, já que em relação aos demais membros da sociedade o grupo era marginalizado.

Assim, não é exagero afirmar a existência de uma sociabilidade específica no acampamento. Em todos os depoimentos, destacam-se as reuniões, as comissões, a união e até mesmo os medos pertinentes a interações sociais mais intensas em comparação às atuais. Uma série de fatores contribuía para isso, mas conseguir assentar-se em uma gleba de terra propiciava ao grupo uma coesão inalcançável posteriormente, alicerce para a resistência a uma série de barbáries, privações e sofrimento. Todo esse processo coaduna-se com a perspectiva de Lezana (2003) ao atribuir a resistência e perseverança de um grupo a atuação dos agentes integradores, no caso os trabalhadores rurais e o apoio das instituições associadas à organização e subsistência necessária a efetivação do assentamento.

A convivência, desde a fase de acampamento, criou vínculos de solidariedade ainda presentes no cotidiano dos assentados. Entretanto, o grau de coesão experimentou alteração em razão da redução das ações coletivas, pois, com a posse da terra, várias atividades, antes desenvolvidas em conjunto, passaram a ser realizadas individualmente nos lotes. Coexiste a divisão simples do trabalho nos assentamentos com ações de cooperação. No assentamento São Domingos dos Olhos D’Água, são exemplos os tanques de resfriamento de leite e as fábricas de queijo, farinha e a padaria. Os assentados procuram organizar a forma de produção para viabilizar a permanência das famílias assentadas em seus respectivos lotes. As 86 famílias assentadas, de forma mais intensa ou superficial, participam da Associação dos Assentados ou das cooperativas existentes, a Cooperativa Mista dos Agricultores Familiares de Goiatuba-Goiás-COOMAFAGO e a Cooperativa Mista Solidária dos Agricultores Familiares da Reforma Agrária de Morrinhos -GoiásCOOP-SAFRA.

A Associação de Moradores do Assentamento São Domingos dos Olhos D’Água é a personalidade jurídica do assentamento. Sua sede é na residência do 
antigo proprietário da fazenda São Domingos dos Olhos D’Água. No local, há um pequeno comércio na forma de minimercado para o atendimento dos assentados. $A$ Associação dos Moradores do Assentamento São Domingos dos Olhos D’Água realiza eleição para a sua presidência a cada dois anos. É por meio das associações/cooperativas que quase todos os assentados comercializam seus produtos. No caso do leite, por exemplo, é norma do Ministério da Agricultura a manutenção do produto resfriado, e como um tanque para resfriamento é caro e comporta um volume relativamente grande para a produção de cada assentado, todos os produtores de leite do assentamento se associaram para comprá-lo.

Diante dos números existentes nos livros contábeis das cooperativas, percebe-se que todos os assentados filiados às mesmas conseguem produzir o suficiente para utilização de todos os recursos disponibilizados com o Programa de Aquisição de Alimentos e Doação Simultânea, que no ano de 2013 foram R\$ 19.800,00 para aquisição e $\mathrm{R} \$$ 4.500,00 para Doação Simultânea. Nas atas da associação, percebe-se que as limitações, para ampliar o volume de venda, na maioria dos casos, estão relacionadas à produção e à regularidade da oferta. Há a necessidade de processamento para verticalizar e agregar valor aos produtos. As dificuldades de se certificar ou mesmo conseguir alvará para o processamento também são fatores limitadores da oferta, por parte dos assentados, de todo o mix requisitado nos editais do PAA no caso 56 produtos.

Segundo Leite et al.(2014), as associações buscam satisfazer a exigência do Estado quanto à necessária representação jurídica dos assentados. Sua criação é obrigatória para o repasse de créditos. São também apoios importantes nas relações dos assentados com entidades externas ao assentamento. Todas essas organizações contribuem para uma maior integração do grupo e, ao mesmo tempo, concedem identidade social. As organizações também significam estrutura de fortalecimento da identidade econômica, social e política dos assentados. Nas palavras de Bourdieu (1992), para construção dessa identidade, os grupos são levados a conflitos, dada a trajetória social que, por sua vez, está associada ao hábito e aos costumes anteriormente vividos, que reforçam laços de solidariedade na competição por bens materiais escassos.

\section{Processos identitários no assentamento}

Os assentados do PA São Domingos dos Olhos D'água são, basicamente, migrantes de outros municípios de Goiás e naturais de vários outros estados brasileiros, apesar de se contabilizar entre eles considerável número de pessoas naturais de Morrinhos. Esses assentados, em momento anterior à instalação do assentamento, viviam de maneira instável com relação à empregabilidade no mundo do trabalho, e acampar, ocupar ou, como ainda afirmam alguns, invadir a área de uma fazenda e disputar o território com o fazendeiro não estava no horizonte de possibilidades dessas pessoas. Eles eram acostumados a entrar em uma fazenda convidados ou contratados pelo proprietário para realização de alguma tarefa. Os assentados respeitavam a propriedade alheia, sentimento constituinte da economia moral dos pobres (THOMPSON, 1998). Ocupar, invadir ou acampar para esses sujeitos eram práticas ilegais. Eles não compreendiam muito bem o processo de desapropriação de uma área para reforma agrária, e não eram 
familiarizados com a atuação dos movimentos sociais de luta pela terra com ações de enfrentamento. Por isso, quando inqueridos se foram pessoas ou movimentos sociais responsáveis por colaborar com o processo ocupação e posse da terra, afirmaram categoricamente que foram pessoas. Todavia, no decorrer da pesquisa, identificaram essas pessoas como líderes das entidades envolvidas com 0 enfrentamento (INCRA, CPT, FETAEG e STRM). É importante registrar que, apesar da aplicação da filosofia e demais mecanismos disseminados pelo MST, este não participou diretamente do processo de ocupação e posse do território. Conforme mensurado, a forma mais acentuada de aquisição de um lote no assentamento foi o sorteio, com 59 incidências, seguido da compra com oito, e outros cinco, dos 72 entrevistados, estão assentados por substituição entre familiares. Na forma sorteio, incidiram $82 \%$ do assentamento, pelo fato de ser o critério acordado entre o INCRA e as lideranças do acampamento para distribuição dos 86 lotes. Registraram-se trocas de parcelas entre os beneficiários, fato não questionado pelo INCRA, pois a maioria dessas permutas objetivava equacionar a qualidade do lote em relação ao perfil do assentado, haja vista que alguns tinham vocação para atividades que não poderiam ser desenvolvidas no lote com o qual foram contemplados. Dos assentados, $11 \%$ declararam que compraram o lote. Na realidade, compraram as benfeitorias, inclusive avaliadas pelo INCRA, responsável por observar a incapacidade do cedente para permanecer no lote e o perfil do adquirente. Nesses casos, o cedente precisa estar acometido de alguma doença ou incapacidade física impeditiva para a permanência no lote, e o comprador necessariamente precisava enquadrar-se nas inúmeras normas sobre procedimentos para seleção de candidatos ao Programa Nacional de Reforma Agrária.

O depoimento de um dos líderes que formou o grupo de 85 famílias para a ocupação reflete como foi a participação do INCRA no processo de regularização do assentamento:

o INCRA estava do nosso lado, e sempre ajudou muito na regularização. Só foi demorada porque a lei é do lado do mais fortes. O sr. Lindolfo entrou com muitos recursos na justiça, mas perdeu todos. Muitos desses recursos era só para ganhar tempo. (ENTREVISTA 54, 2014).

A boa impressão causada no início pelo INCRA, com o tempo foi se desfazendo, a ponto de ser praticamente unânime a opinião de que o órgão dedicava maior atenção aos trabalhadores rurais na fase de acampamento, em comparação à fase de assentamento. Quanto à prefeitura de Morrinhos, município sede do assentamento, na opinião dos entrevistados, pouco contribuiu na fase de acampamento, e agora também sua atuação não pode ser elogiada, pois seu dever é arrumar as estradas, mas é a prefeitura de Goiatuba, município limítrofe com o de Morrinhos, cuja zona urbana fica apenas a $15 \mathrm{~km}$ do acampamento, a responsável por executar esse tipo de tarefa.

Na pesquisa de campo, também se verificou que os assentados gostam tanto do lugar do assentamento como das pessoas que o integram. Sentem-se ligados à terra e à causa, e não gostariam de morar em outro local, especialmente na cidade. Quanto ao que eles sentem falta na vida, principalmente do local de origem, destaca-se a falta da convivência com parentes e amigos. Em relação ao tipo de problemas que o parceleiro ou a sua família enfrentam por morar no assentamento, 
não foi registrada nenhuma situação de destaque ou registro, pois todos estão satisfeitos com o acesso à cidade e com a assistência aos estudantes que dispõem de transporte escolar regular. $O$ transporte também serve para dar suporte àqueles que precisam ir à cidade e não possuem condução própria.

Investigaram-se também quais são os projetos de vida das famílias assentadas. Esses projetos mostram a tendência para quatro áreas prioritárias: a) produção agrícola; b) pecuária leiteira; c) granja de aves e d) industrialização do leite e da mandioca. Os dados apontam que: $45 \%$ dos assentados almejam trabalhar com a produção agrícola de forma que gere grandes excedentes para a comercialização, além do consumo próprio; 35\% pretendem iniciar ou melhorar o rebanho leiteiro com plantel de qualidade e ordenha mecânica; 5\% pretendem trabalhar com a avicultura; $3 \%$ pretendem beneficiar o leite, para fabricação de queijo, e a mandioca para produzir farinha; e $12 \%$ restantes ainda não sabem ao certo em que investir. Os últimos aguardavam a complementação de créditos para sua parcela, por parte do governo, para poder planejar melhor suas atividades, pois foram assentados no transcurso do processo e não alcançaram a liberação de todas as etapas de crédito pelo INCRA.

Esses dados apontam que, após receberem o lote, os assentados têm um rito de liberação de crédito e paulatinamente implementam um projeto de vida voltado para a agropecuária, como esperado pelos órgãos e instituições atuantes nos assentamentos. Às vezes, há demora por conta dos problemas ligados à infraestrutura e à burocracia dos órgãos pertinentes à reforma agrária. Os pesquisados se dizem satisfeitos com a assistência técnica existente no assentamento e ressaltam sua contribuição fundamental para a permanência dos assentados na terra. O assentamento contou com os serviços da Cooperativa de Serviços Técnicos Para o Desenvolvimento Rural-COSTEC, que atua em parceria com o Banco do Brasil; do STRM; e da Associação de Moradores do Assentamento São Domingos dos Olhos D'Água. Os assentados também contam com assistência técnica da Agência Goiana de Defesa Agropecuária-AGRODEFESA, da Agência Rural (Agência Goiana de desenvolvimento Rural e Fundiário) e da Secretaria Estadual Agropecuária-SEAGRO.

A assistência técnica direciona a produção dos assentados conforme as necessidades do mercado e também incentiva a inovação sobre sua produção. Os assentados que possuem rebanho leiteiro, com melhoramento genético, recorrem a prestadores de serviços veterinários por serem mais específicos às suas necessidades. A assistência técnica nos assentamentos é uma política pública fundamental para a permanência na terra. Sem ela a existência e o sucesso do assentamento São Domingos dos Olhos D’Água poderiam estar comprometidos, assim como a própria sobrevivência dos trabalhadores rurais ali residentes.

Em relação ao cotidiano dos assentados, relatou-se ser comum a solidariedade para a organização de festas comemorativas e de trabalhos em parceria. A maioria deles tem parentes que residem no assentamento, fato que, segundo Leite (2004, p.117), propicia mais motivação e segurança. Outra característica típica é o empréstimo de ferramentas e outros utensílios entre os assentados. No assentamento, há a utilização de tratores de propriedade individual, de algum assentado em troca de pagamento, por hora, do serviço prestado. Há seis tratores no assentamento, todos de propriedade individual. As próprias políticas 
públicas de fomento à aquisição dessas máquinas estimulam a compra individual; não há projetos governamentais que promovam a propriedade coletiva para uso coletivo.

Nas festas religiosas, esportivas ou comemorativas, reúne-se um número considerável de vizinhos e parentes para confraternizar, geralmente, na casa dos assentados. Eles já programam as atividades sociais quase para o ano todo, principalmente as festas religiosas e os campeonatos de futebol. Durante o processo de reconhecimento do objeto de pesquisa, constatou-se a existência de três templos religiosos no assentamento, todos em construção, porém já em uso, e é bastante significativo o número de católicos e evangélicos na localidade, o que foi empiricamente constatado nas visitas às casas dos assentados. As festas católicas aglutinam muitos assentados em função de, nesses momentos de lazer, haver muita dança e comidas típicas, como nas festas de santos, especialmente a dos Santos Reis, que acontecem nos meses de janeiro e junho de cada ano. Os cultos evangélicos são realizados, geralmente, duas vezes por semana. As missas, uma vez por mês.

Em dez anos de existência, o assentamento São Domingos dos Olhos D'água contou com vários incentivos de políticas públicas, porém elas não são totalmente satisfatórias e só aconteceram após anos de reivindicações dos assentados, reproduzindo a luta e reivindicação à terra. A infraestrutura dos assentamentos reflete diretamente a relação entre o Estado e os assentados. Ao criar um assentamento, o Estado assume a responsabilidade de viabilizá-lo por meio de políticas públicas. No processo, cabe ao Estado aplicar políticas públicas para verificar sua consecução, o tamanho dos lotes, a qualidade dos solos e recursos hídricos, elementos cruciais para o êxito dos assentados. As políticas públicas no assentamento São Domingos dos Olhos D’Água ocorrem de duas maneiras: próximas às eleições ou por reivindicação dos próprios assentados por intermédio de associações cooperativas ou de entidades apoiadoras, como no caso a CPT, FETAEG e STRM. Em face à pesquisa realizada, evidenciou-se que as dificuldades das políticas públicas pertinentes ao assentamento São Domingos dos Olhos D’Água também estão ausentes, de modo geral, no meio rural, especialmente nos territórios em que predomina a agricultura familiar tradicional. Denota-se a insuficiência das políticas públicas dedicadas à agricultura familiar relacionada ou não à reforma agrária.

O depoimento de um dos assentados indica que o espírito de luta de várias pessoas contribuiu para a conquista da terra, juntamente com a participação de algumas instituições:

o trabalho nosso foi feito como de formiguinha, nós íamos em cada local que os companheiros estava, escondido do dono da fazenda e convidava o trabalhador para encontros que sempre estrategicamente fazíamos nas escolas rurais e geralmente era dia de batizado ou aniversário de alguém. Naquela época havia muitas escolas na zona rural. Lembro que em apenas uma semana nós fizemos mais de 300 carteiras lá no sindicato de Morrinhos, chegou a acabar o papel e teve que buscar mais em Goiânia. E junto de nós, veio os fiscais do trabalho e fiscalizou algumas propriedades e aí, sabe o que aconteceu nê, os fazendeiros logo em toda região ficou sabendo o que nós tínhamos feito. Eu e o (...) (assentado entrevista 11) recebemos muitas ameaças, houve um tempo que solicitamos segurança e fomos atendidos, nós andávamos escoltados pela polícia, todo dia 
recebíamos ligações anônimas de ameaça de morte, mas graças a Deus correu tudo bem. A partir daí o trabalhador, além de já ter consciência de seu direito de trabalhar com carteira assinada, tinha também um lugar para ser apoiado, ser ouvido e o mais importante, ser atendido. (ENTREVISTA 16, 2014).

Esses foram os primeiros passos que os trabalhadores rurais realizaram para o acesso à terra, possíveis com a conscientização sobre a função social da propriedade rural. As redes e grupos foram construções criadas no processo de luta por identidade social dos assentados. A luta, os processos de mobilização, bem como o reconhecimento institucional da demanda foram responsáveis por reforçar laços de solidariedade, união e proximidade quando os atores envolvidos construíram importantes alianças que garantiram o êxito de suas primeiras demandas.

\section{Considerações finais}

Neste artigo, discutiu-se como a ação dos movimentos sociais de luta por acesso à terra promove mudanças não restritas à apropriação da terra, estendendose à constituição de uma identidade territorial na medida em que o acesso ao assentamento rural se estabelece e consolida. Essa premissa é confirmada no caso analisado, o processo identitário estabelecido entre os assentados do assentamento São Domingos dos Olhos D’Água. Para entender como os sem-terra assentados no PA São Domingos, enquanto sujeitos de suas próprias histórias, participaram do processo de territorialização do assentamento, procurou-se verificar como esses trabalhadores inseriram-se em redes sociais estabelecidas ao longo do tempo entre os próprios assentados e as entidades mediadoras entre o Estado e trabalhadores rurais. Observou-se a construção de estratégias de ação que culminaram em ações identitárias em paralelo à intervenção, por parte do Estado e demais instituições representativas dos interesses dos trabalhadores rurais, no conflito pelo território em razão da necessidade de uma atuação coletiva para obtenção do assentamento.

Note-se, essa identidade é fluída, pois se estabelece e se define em razão das condições experimentadas no presente. Um presente, segundo Santos (2008), marcado com a crescente presença de movimentos de racionalização do sujeito e do espaço. Sérgio et al. (2004) afirmam que a partir da criação do projeto de assentamento surgem novas dinâmicas e artifícios de criação de espaços sociais por meio, por exemplo, de redes de sociabilidade, com distinção entre as ações anteriores a efetivação do assentamento e a posterior ocupação da terra. No caso analisado, essas redes foram formadas a partir dos troncos familiares comuns e de famílias oriundas de outras comunidades. As relações já existentes, reforçadas com as ações promovidas por mediadores e pelo Estado, possibilitam redes de sociabilidade, suporte à participação e permanência dos trabalhadores nos processos de territorialização do assentamento estudado.

Segundo Gorgen e Stédile (1991), um exemplo dessas relações são as cooperativas agrícolas nas áreas de assentamento, que funcionam como mecanismos capazes de fomentar e fortalecer a luta pela transformação da sociedade. Na ótica desses autores, os assentados tornam-se agricultores e também 
agentes transformadores da cultura local, envolvendo-se nas transformações das dimensões ideológica, política, filosófica, social, econômica e religiosa, fomentando assim um capital social significativo. Nesse diapasão, caracteriza-se o conceito de capital social defendido por Putnam (2006), relativo ao grau de confiança existente entre diversos atores sociais, com a formação de redes, normas e confiança que facilitam a coordenação e a cooperação para benefício mútuo, práxis vivenciada no território estudado. Percebe-se, a partir da perspectiva do capital social, a confirmação de que demandas sociais são atendidas mais facilmente quando os atores as reivindicam por intermédio de grupos organizados da sociedade civil, realidade facilmente encontrada no PA estudado, em que pontes, casas, estradas, eletrificação rural, entre outros benefícios, são conquistas de reivindicações do coletivo organizado em associação, cooperativa e/ou sindicato.

A investigação das relações de poder estabelecidas entre os trabalhadores rurais e os demais agentes sociais envolvidos no processo de ocupação e posse do território estudado leva os participantes à internalização de uma identidade enquanto cidadãos e sujeitos políticos com direito à inclusão. Desse advento, constituem-se conflitos entre os próprios trabalhadores rurais e também entre esses e os demais agentes envolvidos no processo de ocupação e posse do território, próprios das condições inerentes à estruturação do assentamento, com a passagem de uma forma integralmente coletiva de organização durante a fase de assentamento à perspectiva, por vezes, individual, de trabalho com a gleba. Essa tensão está presente nos depoimentos apresentados no artigo quando da comparação da percepção de maior solidariedade durante a luta pela terra em comparação ao momento posterior.

Os assentamentos rurais, portanto, criam paradigmas que vão além do processo político-social, pois apenas o ato institucional de sua criação não encerra a dinâmica social pertinente ao assentamento. A formalização encerra o processo político-social com a intervenção do Estado quebrando o monopólio da terra e o conflito fundiário. Entretanto, inicia-se outro com a constituição de um novo território, onde emerge uma organização social, política e econômica balizada por relações de produção, poder e conflitos.

\section{REFERÊNCIAS}

ABRAMOVAY, R. O capital social dos territórios: repensando o desenvolvimento rural. Revista de Economia Aplicada, São Paulo, v. 4, n. 2, 2000.

BARDIN, L. Análise de conteúdos. Trad. Luís Antero Reto e Augusto Pinheiro. Lisboa: Edições 70. 1997.

BECKER, D. F.; BANDEIRA, P S. Participação Social e Cidadã no Desenvolvimento Regional Contemporâneo. In: LÜBECK, E., SCHNEIDER, F. M. (Orgs.). Programa de Desenvolvimento Integrado e Sustentável da Mesorregião Metade Sul. Santa Maria Pallotti, 2003.

BERGAMASCO, S. M.; NORDER, L. A. C. O que são assentamentos rurais. São Paulo: Brasiliense, 1996. 
BOURDIEU, P. Economia das trocas simbólicas. $3^{a}$ ed. São Paulo: Editora Perspectiva, 1992.

CPT. Boletim da Comissão Pastoral da Terra: Notícias da Terra e da Água. Ano 24 Goiânia, Goiás. Edição nº 18 de 2011 - De 14 a 28 de dezembro 2011.

FERNANDES, B. M. Movimento social como categoria geográfica. Terra Livre, São Paulo, n.15, p.59-85, 2000.

FERNANDES, B. M. Movimentos socioterritoriais e movimentos socioespaciais: contribuição teórica para uma leitura geográfica dos movimentos sociais. Revista Nera, Presidente Prudente: Unesp, ano 8, n. 6, p. 14 - 34, jan./jun. 2005.

FRANCO, M. L. P. B. Análise de conteúdo. Brasília: Plano Editora. 2003.

GORGEN, F.A.S.. STÉDILE, J.P. (Orgs). Assentamentos: Resposta Econômica da Reforma Agrária. Petrópolis: Vozes, 1991.

HAESBAERT, R. O mito da desterritorialização: do fim dos territórios à multiterritorialidade. Rio de Janeiro: Bertrand Brasil, 2004.

IANNI, O. Ditadura e Agricultura. O desenvolvimento do capitalismo na Amazônia: 1964-1978. 2. ed. Rio de Janeiro: Civilização Brasileira, 1986.

LEITE, S. et al. Impactos dos assentamentos: um estudo sobre o meio rural brasileiro. Brasília: Instituto Interamericano de Cooperação para a agricultura: Núcleo de Estudos Agrários e Desenvolvimento Rural; São Paulo: EDUNESP. (2004).

LEZANA, A.. G. R., et al. Empreendedorismo e parceria. XXIII ENCONTRO NAC. DE ENG. DE PRODUÇÃO. Anais... - Ouro Preto, MG, Brasil, 2003.

MAGNO, L. Territorialização, conflitos e construção das identidades no assentamento rural Aurora em Descalvado - SP. Universidade Federal de Viçosa, junho de 2011.

MARTINS, J. S. A militarização da questão agrária no Brasil. Petrópolis, Vozes, 1984.

NERA - Núcleo de Estudos, Pesquisas e Projetos de Reforma Agrária. Relatório preliminar do DATALUTA - Banco de Dados da Luta Pela Terra. Presidente Prudente: NERA, 1999.

OLIVEIRA, A. U. de. A agricultura camponesa no Brasil. $3^{a}$ ed. São Paulo: Contexto, 1997.

PUTNAM, R. D. Comunidade e democracia: a experiência da Itália moderna. Trad. Luiz Alberto Monjardim. $5^{a}$ ed. Rio de Janeiro: FGV, 2006. 
Reforma Agrária e territorialização da agricultura familiar: o caso do Assentamento São Domingos dos Olhos D'Água/Morrinhos (GO)

RAFFESTIN, C. Por uma Geografia do Poder. São Paulo: Ática, 1993.

SANTOS, M. Por uma outra globalização - do pensamento único à consciência universal. São Paulo: Record, 2008.

SAQUET, M. A. Abordagens e concepções sobre território. $1^{a}$ ed. São Paulo: Expressão Popular, 2007.

SAQUET, M. A.; SANTOS, R. A. Geografia agrária. $1^{a}$ ed. São Paulo: Expressão Popular, 2010.

SERGIO, L. et al. Impactos dos assentamentos um estudo sobre o meio rural brasileiro. São Paulo: UNESP, 2004.

SILVA, C. M. R. B. A Cidade de Morrinhos uma Abordagem Geográfica. Goiânia: GRAFSET - Gráfica e Editora, 2006.

SILVA, J. G. da. Caindo por Terra: Crises da Reforma Agrária na Nova República. São Paulo: Busca Vida, 1987.

SILVA, J. G. O que é questão agrária, $3^{a}$ ed. São Paulo: brasiliense, 1981.

SILVA, J. M. P. da. Poder, governo e território na sociedade contemporânea. Série Estudos e Ensaios / Ciências Sociais/ FLACSO-Brasil - junho /2009.

SOUZA, M. J. L. O Território: Sobre Espaço e Poder, Autonomia e Desenvolvimento. In:CASTRO, et. al.(Orgs.). Geografia: Conceitos e Temas, Rio de Janeiro:Bertrand Brasil,1995.

STÉDILE, J. P. A Questão Agrária e o Socialismo. In: ESTEDLE, João Pedro et. al. (Orgs.). A Questão Agrária Hoje. Porto Alegre; Universidade / UFRGS, 2002.

TEIXEIRA, E. C., \& MARTIN, M. A. Retornos aos investimentos no setor não agrícola e agrícola da economia brasileira. Revista de Econometria, 1988.

THOMPSON, E. P. Costumes em comum. São Paulo: Companhia das Letras, 1988.

TURNER, V. O Processo Ritual: estrutura e antiestrutura. Petrópolis: Vozes, 1974.

VEIGA, J. E da. Desenvolvimento sustentável: o desafio do século XXI. Rio de Janeiro: Garamond, 2005.

WANDERLEY. M. N.B. A agricultura familiar no Brasil: um espaço em construção. São Paulo: Mimeo, 1995. 
Moacir José dos Santos. Docente e pesquisador do Mestrado em Planejamento e Desenvolvimento Regional. professormoacirsantos@gmail.com

Alzair Eduardo Pontes. Professor da FFaculdade de Filosofia e Ciências Humanas de Goiatuba. alzairpontes@hotmail.com 